\title{
PROTEÍNA G - MECANISMOS MOLECULARES DE COMUNICAÇÃO CELULAR
}

Diógenes O. Silva, Najlah R. M. Ahmad, Iberê C. Soares, Cristiane K. Kraemer, Sandro O. Buss e Carlos Fernando de Mello Departamento de Química - Centro de Ciências Naturais e Exatas UFSM, Santa Maria, RS

\section{SUMMARY}

In the present paper the authors comment on the physiological role of $\mathrm{G}$ proteins in transmission signalling process and some alterations of this system. The review is directed to beginners and emphasize a visual approach to the theme

Alfred Goodman Gilman e Martin Rodbell receberam o Nobel de Fisiologia em 1994 por seus trabalhos relevantes na área de comunicação celular, especificamente na área de transdução do sinal hormonal. Estes trabalhos mostraram as bases fisiopatológicas de doenças importantes como o cólera e alguns tipos de tumores (adenoma). Pela relevância médica dos trabalhos destes pesquisadores, apresentamos a seguir uma revisão sobre o tema, intencionando dar ao leitor uma visão geral sobre os mecanismos básicos de comunicação celular

Hormônios e neurotransmissores atuam como elementos de comunicação celular (primeiros mensageiros) e modulam o funcionamento dos vários tecidos e órgãos de modo a manter a homeostasia do organismo. Entretanto, a maioria deles não entram na célula que recebe a mensagem (céluta-alvo). O sinal hormonal é comunicado através da membrana plasmática, por proteinas integrais de membrana chamadas receptores. Estes receptores estão acoplados a um 
sistema de transmissão de sinal através da membrana plasmática, chamado de sistema de transdução do sinal. Uma vez ativado, este sistema desencadeia a produção de segundos mensageiros no interior da célula-alvo, que por sua vez atuam sobre enzimas e outras proteinas (efetores), provocando as alterações metabólicas características do hormônio (Figura 1). Falaremos a seguir sobre estes mecanismos de transdução, cujo mecanismo básico é comum a vários receptores dos mais diversos hormônios e neurotransmissores.

A interação do hormônio com o receptor representa somente o primeiro passo na cascata de eventos que envolve a transdução do sinal e a ação do hormônio. Entre a ligação do hormônio ao receptor e a ação do efetor, uma proteina chamada Proteina $G$ atua com elemento intermediário. A proteina $\mathrm{G}$ é composta de três subunidades distintas, denominadas $\alpha, \beta$ e $\gamma$; e é assim chamada porque a subnidade $\alpha$ é capaz de ligar nucleotídeos da guanina (GDP e GTP). Seguiremos passo a passo estes eventos, mostrando de que forma ocorre a transmissão do sinal, e a participação de cada uma das subunidades da proteina $G$ neste processo.

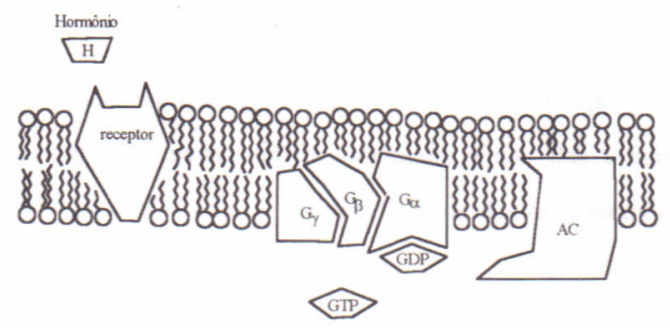

1.Estado Basal: O receptor não está ocupado. A proteina $G$ está na forma de heterotrimero (as três subunidades unidas entre si), e a subunidade $\alpha$ apresenta uma molécula de GDP ligada, o que deixa esta subnidade inativa. O efetor (neste exemplo, colocamos a enzima adenilato ciclase - AC- como efetor) também se encontra no estado inativo.

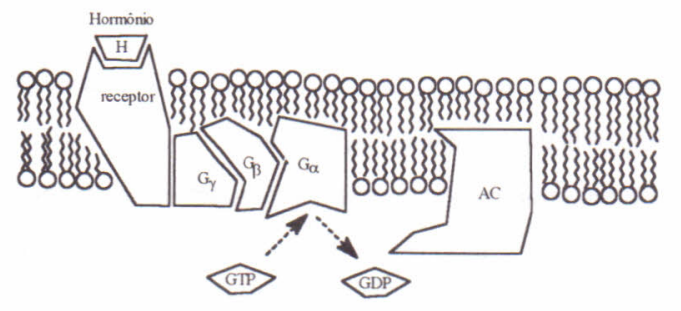

2.0 hormônio se liga ao receptor, provocando uma alteração conformacional. O receptor interage com o heterotrímero, produzindo uma alteração conformacional no complexo e 
deslocando o GDP da subunidade $\alpha$. O GTP se liga ao sítio anteriormente ocupado pelo GDP na subnidade $\alpha$, ativando-a.

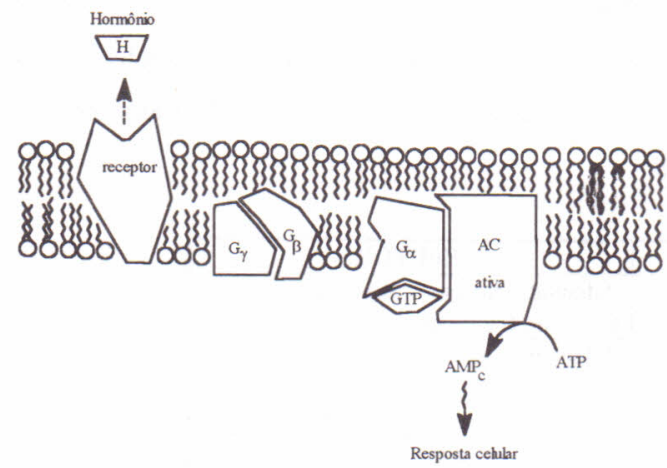

3.A ligação do GTP à subunidade $\alpha$ provoca uma diminuição na afinidade do receptor pelo hormônio, liberando-o. De maneira semelhante, diminui também a afinidade entre as moléculas do heterotrímero, e a subunidade $\alpha$ ativada se dissocia do complexo $\beta \gamma$ (que teria uma função de ancoramento da subunidade $\alpha$ à membrana), e se liga ao efetor, ativando-o. A proteina efetora (adenilato ciclase), fica ativada gerando o segundo mensageiro (neste caso, é o $\mathrm{AMP}_{\mathrm{c}}$ ).

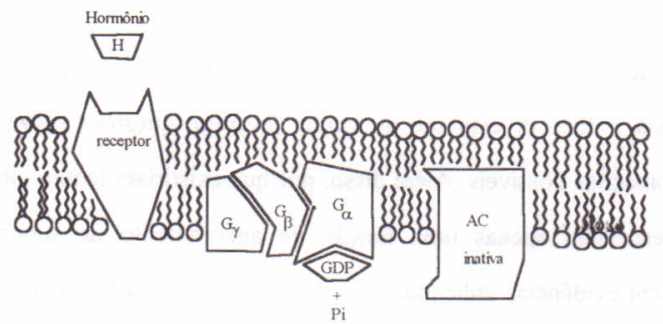

4.Após ativar a proteina efetora, a subunidade $\alpha$ termina seu efeito através da hidrólise do GTP ligado, transformando-o em GDP e se dissociando do efetor. Esta hidrólise é catalisada pela própria subunidade $\alpha$, que possui uma atividade GTPásica. A presença do GDP aumenta a afinidade da subunidade $\alpha$ pelas subunidades $\beta$ e $\gamma$, recompondo o heterotrimero e voltando todo sistema ao estado basal.

As proteinas $\mathrm{G}$ foram inicialmente classificadas de acordo com 0 papel desempenhado pela subunidade $\alpha$. No nosso exemplo mostramos uma proteina G cuja subunidade $\alpha$ tinha um papel estimulatório da adenilato ciclase, e portanto se tratava de uma proteína $G_{S}$ (do inglês stimulatory). Se esta proteina $\mathrm{G}$ tivesse um papel inibitório sobre a adenilato ciclase, ela seria uma proteina $G_{i}$. Atualmente, esta classificação vem sendo abandonada, e uma nova nomenclatura 
baseada na homologia da sequência de aminoácidos das várias proteínas $\mathrm{G}$ tem sido proposta. Por isso, algumas proteinas $\mathrm{G}_{i}$ não terão ação sobre a adenilato ciclase, mas sim sobre outro efetor, que pode ser, por exemplo, uma fosfodiesterase específica para GMPc. De qualquer maneira, como não é nossa intenção esgotar o assunto, mostraremos, no quadro abaixo, algumas proteínas $\mathrm{G}$ e o efetor associado a título de ilustração.

\begin{tabular}{|l|l|}
\hline Proteina & \multicolumn{1}{|c|}{ EFETOR } \\
\hline Gs & $\begin{array}{l}\text { Adenilato ciclase - ativação } \\
\text { Canal de } \mathrm{Ca}^{2+} \text { - abertura }\end{array}$ \\
\hline Golf & Adenilato ciclase - ativação \\
\hline Gt1 & Fosfodiesterase GMPc - ativação \\
\hline Gt2 & Fosfodiesterase GMPc - ativação \\
\hline Gi1, Gi2, Gi3 & $\begin{array}{l}\text { Adenilato ciclase - inibição } \\
\text { Canal de } \mathrm{K}^{+}-\text {abertura } \\
\text { Canal de } \mathrm{Na}^{+}-\text {fechamento }\end{array}$ \\
\hline Go & $\begin{array}{l}\text { Canal de } \mathrm{Ca}^{2+} \text { - fechamento } \\
\text { Fosfolipase C - ativação }\end{array}$ \\
\hline $\mathrm{Gz}$ & desconhecido \\
\hline $\begin{array}{l}\text { Gq, G11, G14, } \\
\text { G15/16 }\end{array}$ & Fosfolipase C - ativação \\
\hline G12, G13 & desconhecido \\
\hline
\end{tabular}

Foram identificados até 1994, através de clonagem gênica, vinte e uma subunidades $\alpha$ diferentes, quatro $\beta$ e seis $\gamma$. Esta diversidade molecular levantou questões sobre as funções destas subunidades e as combinações possiveis. Além disso, por que existiriam tantas subunidades $\beta$ e $\gamma$ diferentes, se estas exercessem apenas uma função de ancoramento da subunidade $\alpha$ à membrana? Atualmente existem evidências indicando que o complexo $\beta \gamma$ participa no processo de ativação da proteina $\mathrm{G}$, interagindo com receptores e proteinas efetoras. A nivel de receptor, existem evidências mostrando que o tipo de subunidade $\beta \gamma$ associada modifica a capacidade da subunidade $\alpha$ de ligar GTP. A nivel de proteinas efetoras têm sido demonstrado que existem algumas isoformas de adenilato ciclase (AC) que são reguladas pelo complexo $\beta \gamma$. O subtipo I é inibido pelo complexo $\beta \gamma$, e os subtipos II e IV são estimulados. O efeito estimulatório do complexo $\beta \gamma$ sobre a AC subtipo II e IV, é, entretanto, dependente da presença da subunidade $\alpha$ s, o que confere um papel modulatório à subunidade $\beta \gamma$. Por outro lado, o efeito inibitório sobre a AC tipo I, não depende da presença da subunidade $\alpha$, o que demonstra um papel independente da subunidade By como elemento ativo na transdução do sinal através da membrana plasmática.

Alterações em propriedades da proteina $\mathrm{G}$, como perda da atividade GTPásica da subunidade $\alpha$, podem levar a estados de ativação permanente do sistema transdução. $O$ desenho 
abaixo ilustra algumas destas alterações que podem levar a uma modificação nos níveis celulares de AMPc:
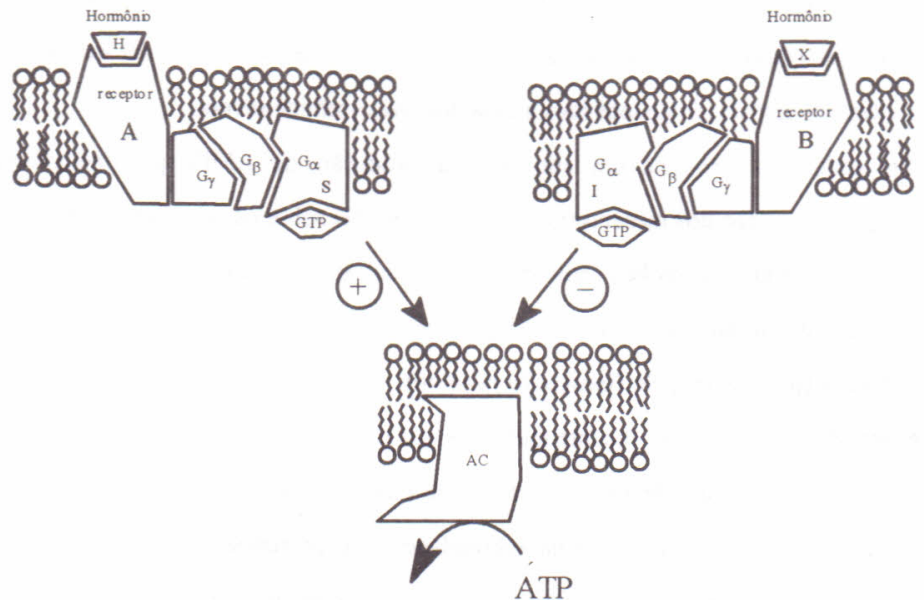

$\mathrm{AMP}_{\mathrm{c}}$

A adenilato ciclase, enzima que forma AMPc está sob a regulação simultânea das proteinas $\mathrm{G} i$ e $\mathrm{Gs}$, que se encontram associadas a tipos diferentes de receptores. O receptor A do hormônio H está associado a uma Gs, e sua estimulação leva a um aumento na produção de AMPc. Por outro lado, o receptor B do hormônio X está associado a uma Gi, e portanto, a ação do hormônio X é a diminuição na concentração de AMPc intracelular

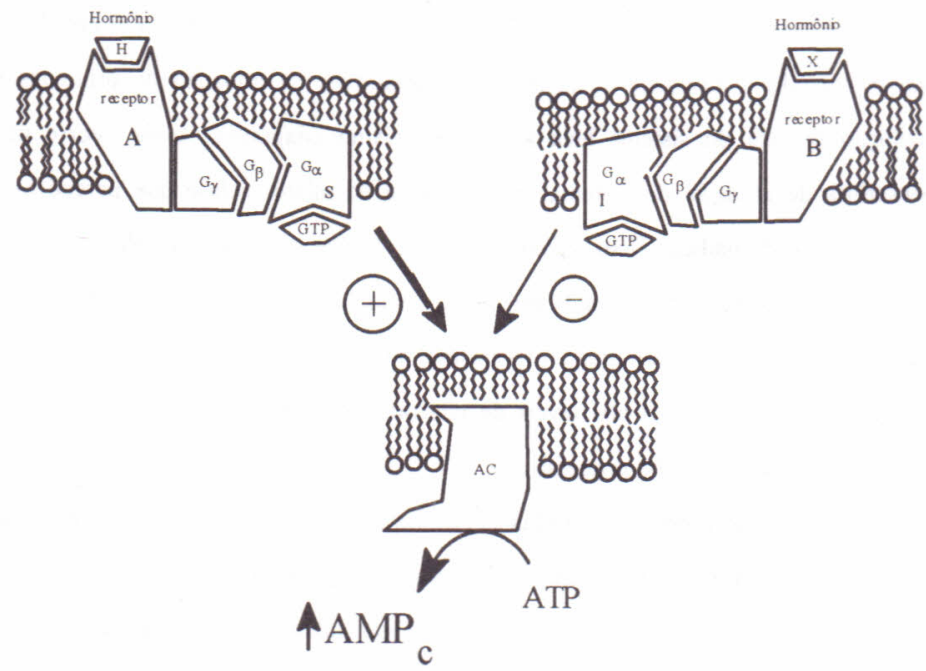


Uma produção aumentada de AMPc pode resultar de uma ativação da Gs, por um aumento na produção celular de $\mathrm{G} s$, mutação ou modificação estrutural catalisada por toxina colérica. No caso da toxina colérica, o aumento na atividade adenilato ciclásica, leva a um aumento nos niveis de AMPc das células do epitélio intestinal, com alteração na permeabilidade celular e no fluxo de íons no intestino. Este fluxo de ions leva a uma diarréia osmótica severa.

Em todos os casos há um aumento na produção de AMPc por mecanismos relacionados a uma sobreposição dos mecanismos relacionados à $\mathrm{Gs}$ sobre os relacionados à Gi. Por outro lado, o mesmo resultado metabólico (aumento na concentração de AMPc) pode ocorrer por diminuição da atividade da $\mathrm{G} i$. Isto ocorre através de modificações estruturais induzidas por toxinas como a toxina pertussis (produzida pela Bordetella pertussis, a bactéria causadora da coqueluche), diminuição na expressão de $\mathrm{G} i$, e possivelmente mutações que inativem $\mathrm{G} i$.

Recentemente foram identificados sítios de palmitoilação (adição de uma molécula de palmitato - ácido graxo de 16 carbonos) na subunidade $\alpha$ de proteínas Gs. Este fenômeno é desencadeado somente pela presença de um agonista (no caso, adrenérgico), e pode representar um possivel mecanismo de regulação da atividade da subunidade $\alpha$. Até agora, entretanto, não foi definido se esta palmitoilação modifica a atividade da subunidade $\alpha$. Sabe-se somente que ela facilita a interação da subunidade $\alpha$ com a membrana. Por outro lado, a exposição de células a agonistas de receptores ligados à proteinas $\mathrm{G}$ causa uma alteração nos niveis celulares destas proteínas, provavelmente através de mecanismos envolvendo transcrição e tradução. Através deste mecanismo, as proteinas $G$ devem participar do fenômeno de dependência de drogas, particularmente na dependência a opióides. Os opióides atuam sobre neurônios do locus ceruleus e mucleus accumbens inibindo a atividade adenilato ciclásica através da ativação de proteinas $G$ inibitórias. A inibição crônica do sistema leva a um mecanismo adaptativo, onde ocorre uma resposta compensatória de ativação do sistema envolvendo a adenilato ciclase que parece estar associado ao fenômeno de drogadição. Esta ativação crônica parece ser mediada pela diminuição nos niveis de proteinas Gi e Go, , pelo menos no que diz respeito ao mucleus accumbens. Isto, entretanto, parece não se constituir no único mecanismo de desenvolvimento do fenômeno de drogadição, e alterações concomitantes nos niveis de neurotransmissores como a dopamina, por exemplo, também têm papel relevante no processo.

Em função da sua presença em todas as células, as proteínas $\mathrm{G}$ certamente receberão muito mais funções das que as atualmente descritas, e a exploração destes mecanismos abrirá não só novas portas para o entendimento do fenômeno da comunicação celular, como outras áreas, como a farmacologia, será beneficiada pelo desenvolvimento potencial de drogas que atuem a nível de 
proteina G. Uma abordagem mais detalhada sobre os sistemas efetores especificos modulados por proteínas $\mathrm{G}$ e suas eventuais alterações pode ser obtida nas referências que seguem.

\section{REFERÊNCIAS}

Exton, J.H. (1994). Phosphoinositide phospholipases and G proteins in hormone action, Ammual Review of Physiology, 56, 349-369

Gilman, A.G., Rall, T.W. Nies, A.S., Taylor, P. (1990). The Pharmacological Basis of Therapeutics, Pergamon Press, New York.

Hepler, J.R. \& Gilman (1992). G Proteins, Trends in Biochemical Sciences, 17, 383-387

Hille, B. (1992). G protein-couple mechanisms and nervous signalling. Neuron, 9, 187-195.

Kobilka, B. (1992). Adrenergic receptors as models for G protein-coupled receptors. Ammial Review of Neuroscience, 15, 87-114.

Lad, P.M., Welton, A.F. \& Rodbell, M. (1977). Evidence for distinct guanine nucleotide sites in the regulation of the glucagon receptor and of adenylate cyclase. Journal of Biological Chemistry, 252, 5942-5946.

Lefkowitz, R.J., Cotecchia, S., Samama, P. \& Costa, T. (1993). Constituitive activity of receptors coupled to guanine nucleotide regulatory proteins. Trends in Pharmacological Sciences, 14, 303-307

Mattera, R., Graziano, M.P., Yatani, A., Zhou, Z., Graf, R., Codina, J., Birnbaumer, L., Gilman, A.G. \& Brown, A.M. (1989). Splice variants of the $\alpha$ subunit of the $G$ protein $G_{s}$ activate both adenylyl cyclase and calcium channels. Science, 243, 804-807.

Milligan, G. (1993). Agonist regulation of cellular G protein levels and distribution: mechanisms and functional implications. Trends in Pharmacological Sciences, 14. 413-418.

Moriarti, T.M., Padrell, E., Carty, D.J., Omri, G., Landau, E.M. \& Iyengar, R. (1990). G ${ }_{0}$ protein as a signal transducer in the pertussis toxin-sensitive phosphatidylinositol pathway. Nature, 343, 7982 .

Müller, S. \& Lohse, M.J. (1995). The role of $\beta \gamma$ subunits in signal transduction. Biochemical Society Transactions, 23, 141-148.

Mumby, S.M. \& Muntz, K.H. (1995). Receptor regulation of G protein palmitoylation. Biochemical Society Transactions, 23, 156-160. 
Nestler, E.J. (1992). Molecular mechanisms of drug addiction, The Journal of Neuroscience, 12, 2439-2450.

Raw, J. D. (1992). Biochemistry, Neil Paterson Publishers, Burlington, North Carolina.

Reynolds, I.J. \& Schmidt, C.J., (1988). Guanine nucleotides are competitive inhibitors of N-methylD-aspartate at its receptor site both in vitro and in vivo. J. Pharmacology and Experimental Therapeutics, 250, 162-169.

Rodnight, R. \& Wofchuk, S. (1992). Roles for protein phosphorylation in synaptic transmission. Essays in Biochemistry, 27, 91-102.

Ross, E.M. (1989). Signal sorting and amplification through G protein-coupling receptors. Neuron, 3, 141-152.

Siegel, G.J., Agranoff, B.W., Albers, R.W. \& Molinoff, P.B. (1994). Basic Neurochemistry, Raven Press, New York.

Spiegel, A.M., Shenker, A. \& Weinstein, L.S. (1992). Receptor-effector coupling by G proteins: Implications for normal and abnormal signal transduction. Endocrine Reviews, 13, 536-565.

Walaas, S.I. \& Greengard, P. (1991). Protein phosphorylation and neuronal function. Pharmacological Reviews, 43, 299-349. 